\title{
Nötrofil-Lenfosit Oranlarının, Platelet Belirteçlerinin ve Sodyum Düzeyinin Febril Nöbetler ile İlişkisi
}

\section{The Association of Neutrophil-Lymphocyte Ratios, Platelet Markers and Sodium Level with Febrile Seizures}

iD Esra Sarıgeçili ${ }^{1}$, iD Habibe Koç Uçar ${ }^{1}$, iD Sinem Sarı Gökay ${ }^{2}$

${ }^{1}$ Adana Şehir Hastanesi, Çocuk Nöroloji Bölümü, Adana, Türkiye

${ }^{2}$ Adana Şehir Hastanesi, Çocuk Acil Bölümü, Adana, Türkiye

\section{$\ddot{O} \mathbf{z}$}

Amaç: Çocuk acil servise febril nöbet ile başvuran hastaların laboratuvar parametrelerini belirlemek ve bunların basit ve komplike nöbet ayrımındaki önemini göstermektir.

Gereç ve Yöntem: Aralık 2019-Mart 2020 tarihleri arasında Adana Şehir Hastanesi Çocuk Acil Bölümü’ne febril nöbet ile başvuran hastaların başvurudan sonra ilk bir saat içindeki nötrofil-lenfosit oranları, platelet değerleri ve sodyum düzeyleri incelendi.

Bulgular: 138 basit ve komplike febril nöbet hastası çalışmaya alındı. 111'i (\% 80,4) basit febril nöbet; 27’si (\% 19,5) komplike febril nöbetti. Nötrofil/lenfosit oranları ile Mean Platelet volüm/platelet oranları arasında basit ve komplike nöbet ayrım bakımından anlamlı bir farklılık saptanmadı ( $\mathrm{p}>0,05)$. Ancak febril nöbet ile başvuran hastaların \% 65,2'de hiponatremi olup basit ve komplike nöbetler bakımından anlamlı farklıllk mevcuttu (p:0,006). Tekrarlayan nöbet riski yönünden farklılık saptanmadı $(\mathrm{p}>0,05)$.

Sonuç: Hiponatreminin febril nöbete yatkınlık sağlayan bir neden olabileceği düşünüldü.

Anahtar kelimeler: Çocuk acil; hiponatremi; platelet; nötrofil; lenfosit

Abstract

Aim: The aim of this study was to determine laboratory parameters of the patients with febrile seizure who was applied to the pediatric emergency department and to show their importance in the distinction of the simple and complicated febrile seizure.

Material and Methods: The neutrophil-lymphocyte ratios, platelet levels and sodium values of the patients who were applied to the Adana City Hospital Training and Research Hospital pediatric emergency department with febrile seizure between December 2019-March 2020 were examined with in the first hour.

Results: 138 simple and complicated febrile seizure patients were included in the study. $111(\% 80,4)$ were simple febrile seizures and $27(\% 19,5)$ were complicated febrile seizures. We did not find any significant difference between neutrophil/lymphocyte ratios and mean platelet volume / platelet ratios in the distinction of simple and complicated febrile seizure ( $p>0,05)$. However, $\% 65,2$ of the patients presenting with febrile seizures had hyponatremia and there was a significant difference between the simple and complicated febrile seizures ( $p: 0,006)$. There was no difference in terms of seizure recurrence risk ( $>0,05)$.

Conclusions: Hyponatremia was thought to be an underlying cause in the etiology of acute febrile seizure.

Key words: Pediatric emergency; hyponatremia; platelet; neutrophil; lymphocyte

Yazışma Adresi: Esra Sarıgeçili Adana Şehir Hastanesi, Çocuk Nöroloji Bölümü, Adana, Türkiye

E-Posta: sarigeciliesra@gmail.com

Alınma Tarihi: 03.06.2020 / Kabul Tarihi: 13.12.2020 / Yayımlanma Tarihi: 20.09.2021

Nötrofil-lenfosit oranı, platelet belirteçleri ve sodyum düzeyi - Sarıgeçili

Genel Tip Derg 2021;31(3)216-220

ve ark 
Febril nöbetler (FN) 6 ay- 6 yaş arası çocukluklarda sık karşılaşılan, ateş ve enfeksiyon ile ilişkili nöbetlerdir. FN'de santral sinir sistemi enfeksiyonu, akut metabolik sorunlar, epilepsiye yatkınlık yaratan nöromotor gelişim geriliği gibi durumlar dışlanmalıdır (1). Basit ve kompleks FN'ler olarak iki gruba ayrılır. Basit olanlar FN'in üçte ikisini oluşturur ve 15 dakikadan kısa süren, fokal özellik göstermeyen ve aynı gün içinde tekrarlamayan nöbetlerdir. Kompleks FN'ler geri kalan üçte birlik kısmı oluşturur ve daha fazla epilepsiye yatkınlık gösteren, fokal nitelik taşıyan, 15 dakikadan uzun süren ve aynı gün içerisinde tekrarlayan nöbetlerdir $(2,3)$. Ailelerin çoğunlukla acil servise başvurdukları zaman nöbetin ne zaman başlayıp bittiğini, ne kadar sürdüğünü ve ne şekilde geliştiğini belirtmeleri zor olabilmektedir. Hastaların prognozlarını ve epilepsiye yatkınlıklarını değerlendirebilmek için komplike ya da basit nöbet ayrımını yapabilmek oldukça önemlidir.

Nötrofil-lenfosit oranları (NE/LE), mean platelet volüm (MPV), platelet sayısı gibi parametreler ulaşılması kolay ve ucuz olup rutinde de oldukça sık kullanılan akut ve kronik inflamatuar olaylarda değişen parametrelerdir. Akut inflamatuar durumlardan akut böbrek yetmezliği, spontan intrakranial kanama, akut influenza gibi durumlar olup kronik durumlardan ise kardiyovaskuler durumlar, stroke, diyabet, ailevi akdeniz ateşi gibi durumlarda düzeylerinin değişebileceği bildirilmektedir $(4,5,6)$.

FN'de gelişen hiponatreminin ateşe sekonder uygunsuz ADH sekresyonu nedeni ile ortaya çıktığı düşünülmektedir. Bunun sonucunda da azalan sodyum düzeyine karşılık hücre içerisine kalsiyum akışı olması ve bu durumun da nöronal eksitabiliteyi daha fazla artırmasının sorumlu olduğu düşünülmektedir. Ayrıca hiponatremi durumunda hücre içine su akışı artar ve hücrenin şişip membran yapısının bozulmasına neden olur. Bu durumun da nöbet eşiğini düşürdüğü tahmin edilmektedir $(7,8)$.

Bu çalışmada acil servise başvuran çocuklarda basit ya da komplike FN durumlarında NE/LE oran1, mean platelet volüm (MPV), platelet sayısı ve bunların oranı (MPV/PLT) arasındaki ilişkiyi belirlemek ve ayrıca tüm FN ve tekrarlayan FN durumlarında hiponatremi ilişkisini araştırmaktır.

\section{Materyal ve Metod}

Çalışmada Aralık 2019-Mart 2020 dönemleri arasında Adana Şehir Eğitim ve Araştırma Hastanesi Çocuk Acil Bölümü’ne basit ya da komplike FN şikayeti ile başvuran 138 hastanın dosyaları geriye dönük incelendi. Çalışmanın yapıldığ yaklaşı 250.000 hastanın başvurduğu üçüncü seviye bir acil servistir. Çalışma için 22/04/2020 tarihli 2020/804 sayılı karar ile etik kurul onamı alınd1.

Çalışmaya dahil edilme kriterleri; Çocuk acil bölümüne başvurmak, 6 ay- 6 yaş arasında olmak, basit ya da komplike FN tanısı olması, santral sinir sitemi enfeksiyonu ya da akut metabolik bir sorun olmaması ve hasta verilerine eksiksiz ulaşılması olarak belirlendi.

Çalışmaya dahil edilmeme kriterleri; Çocuk acil bölümüne başvurmamış olmak, daha öncesinde epilepsi tanısı konması ve altta yatan nöromotor gelişime geriliği olması (serebral palsi, metabolik hastalı), santral sinir sistemi enfeksiyonu ve akut metabolik bir
Tüm hastaların acil serviste bilgileri alınıp rutin ve detaylı nörolojik muayeneleri yapıldı. Hastaların tamamının FN'ten bir saat sonra sodyum, potasyum, kalsiyum, glukoz, kan gazı, hemogram gibi parametrelerine bakıldı. Santral sinir sistemi enfeksiyonu düşünülen tüm hastalar nörolojik görüntülemeleri yapılıp çalışmadan çıkarıldılar.

\section{İstatistiksel yöntem}

Verilerin istatistiksel analizinde SPSS (Statistical Package for the Social Sciences) 23.0 paket programı kullanıldı. Kategorik ölçümler sayı ve yüzde olarak, sürekli ölçümlerse ortalama ve standart sapma (gerekli yerlerde ortanca ve minimum-maksimum) olarak özetlendi. Kategorik değişkenlerin karşılaştırılmasında Pearson Chi-square testi kullanıldı. Çalışmada yer alan parametrelerin normal dağılım gösterip göstermediğini belirlemede Shapiro-Wilk testi kullanıldı. Gruplar arasında sürekli ölçümlerin karşılaştırılmasında dağılımlar kontrol edilerek, normal dağılım gösteren parametreler için bağımsız student t-test, normal dağılım göstermeyen parametrelere de Mann Whitney U testi kullanıldı. Çalışmada hastaların sodyum $(\mathrm{Na})$ oranları baz alınarak sensitivite (duyarlılık) ve spesifite (özgüllük) değerleri hesapland, ayrıca ROC eğrisi altında kalan alan incelenerek, cut off değeri belirlendi. Bağımlı değişkeni etkileyen bağımsız değişkenlerin saptanması için ise multinominal logistik regresyon analizi uygulandı. Tüm testlerde istatistiksel önem düzeyi 0.05 olarak alındı.

\section{Sonuçlar}

Çalışmaya alınan 138 hastanın 111'i (\% 80,4) basit FN; 27'si (\% 19,5) ise komplike FN olup bunların ise 57'si (\% 41,3) k1z, 81'i (\% 58,7) erkekti (p: 0,27). Hastaların yaş ve laboratuvar değerleri Tablo 1'de gösterilmiştir.

Tablo 1: Hastaların laboratuvar değerleri

\begin{tabular}{|c|c|c|c|c|}
\hline & Basit FN & Kompleks FN & Toplam & \\
\hline & & & & p \\
\hline \multirow[b]{2}{*}{ Yaş (ay) } & $27,51 \pm 12,75$ & $26,22 \pm 12,70$ & $27,26 \pm 12,70$ & \multirow[b]{2}{*}{0,602} \\
\hline & & $\left(8_{-}-54\right)$ & $(8-60)$ & \\
\hline WBC & $12,63 \pm 6,24$ & $12,02 \pm 5,18$ & $12,51 \pm 6,03$ & \multirow[b]{2}{*}{0,644} \\
\hline$\left(\mathbf{x 1 0} / \mathrm{mm}^{3}\right)$ & $(3-34)$ & $(2,26-26,10)$ & $(2,69-34,0)$ & \\
\hline \multirow[b]{2}{*}{ CRP (mg/dl) } & $16,24 \pm 20,96$ & $25,97 \pm 57,75$ & $18,13 \pm 31,55$ & \multirow[b]{2}{*}{0,321} \\
\hline & $(0,1-110)$ & $(0,1-2555)$ & $(0,1-255)$ & \\
\hline \multirow[b]{2}{*}{ MPV (fl) } & $7,73 \pm 0,71$ & $7,61 \pm 0,76$ & $7,70 \pm 0,72$ & \multirow[b]{2}{*}{0,439} \\
\hline & $(6,4-10,2)$ & $(6,3-9,2)$ & $(6,3-10,2)$ & \\
\hline \multirow[b]{2}{*}{$\mathrm{Hb}(\mathrm{gr} / \mathrm{dl})$} & $11,15 \pm 1,12$ & $10,69 \pm 1,33$ & $11,06 \pm 1,17$ & \multirow[b]{2}{*}{0,067} \\
\hline & $(6,5-15,4)$ & $(7,1-13,1)$ & $(6,5-15,4)$ & \\
\hline \multirow[b]{2}{*}{ PCT $(\mu \mathrm{g} / \mathrm{L})$} & $0,23 \pm 0,08$ & $0,21 \pm 0,06$ & $0,22 \pm 0,08$ & \multirow[b]{2}{*}{0,344} \\
\hline & $(0,1-0,48)$ & $(0,09-0,42)$ & $(0,09-0,48)$ & \\
\hline \multirow[b]{2}{*}{$\operatorname{PLT}\left(10^{9} / \mathrm{L}\right)$} & $307,34 \pm 108,17$ & $292,3 \pm 107,46$ & $304,4 \pm 107,81$ & \multirow[b]{2}{*}{0,517} \\
\hline & (104-674) & $(126-572)$ & $(104-674)$ & \\
\hline \multirow{2}{*}{$\begin{array}{l}\text { Sodyum } \\
(\mathrm{mEq} / \mathbf{L})\end{array}$} & $134,44 \pm 2,50$ & $135,92 \pm 2,10$ & $134,72 \pm 2,49$ & \multirow{2}{*}{0,006} \\
\hline & $(127-143)$ & $(132-140)$ & $(127-143)$ & \\
\hline Kalsiyum & $9,34 \pm 0,53$ & $9,15 \pm 0,52$ & $9,30 \pm 0,53$ & \\
\hline$(\mathrm{mg} / \mathrm{dl})$ & $(8-10,8)$ & $(8-10,2)$ & $(8-10,8)$ & 0,112 \\
\hline
\end{tabular}

Nötrofil-lenfosit oranı, platelet belirteçleri ve sodyum düzeyi - Sar1geçili ve ark. 


\begin{tabular}{lcccc} 
& $23,69 \pm 12,98$ & $22,47 \pm 15,51$ & $23,44 \pm 13,44$ & \\
Laktat & $(6-69)$ & $(7-74)$ & $(6-74)$ & 0,570 \\
& $7,32 \pm 0,07$ & $7,35 \pm 0,05$ & $7,33 \pm 0,06$ & \\
Ph & $(7,13-7,45)$ & $(7,26 \pm 7,44)$ & $(7,13-7,45)$ & 0,101 \\
\hline
\end{tabular}

Çocuk acil servise FN ile başvuran hastaların ilk bir saat içerisinde bakılan NE/LE ve MPV/PLT oranı ile sodyum düzeylerinin basit ya da komplike FN ile olan ilişkisi Tablo 2'de gösterilmiş olup NE/LE ve MPV/PLT oranları arasında basit ya da komplike FN ayrımında istatistiki bir fark saptanmad. Sodyum düzeylerinde ise basit ve komplike FN arasında anlamlı bir farkl1lı mevcuttu (p: 0,006).

Tablo 2: Basit ya da kompleks febril nöbet geçiren hastaların NE/LE oranı, MPV/PLT oranı ve sodyum düzeyleri ile olan ilişkisi

\begin{tabular}{lcccc}
\hline & Basit FN & Kompleks FN & Toplam & p \\
& Ort \pm ss & Ort \pm ss & Ort \pm ss & \\
\hline NE/LE & $3,69 \pm 4,47$ & $3,18 \pm 3,84$ & $3,59 \pm 4,34$ & \\
& $(0,28-31,21)$ & $(0,09-20,77)$ & $(0,09-31,21)$ & \\
& $0,02 \pm 0,01$ & $0,03 \pm 0,01$ & $0,02-0,01$ & \\
MPV/PLT & $(0,01-0,10)$ & $(0,01-0,06)$ & $(0,01-0,10)$ & 0,571 \\
& $134,44 \pm 2,50$ & $135,92 \pm 2,10$ & $134,72 \pm 2,49$ & \\
\hline $\begin{array}{l}\text { Sodyum } \\
(\mathrm{mEq} / \mathrm{L})\end{array}$ & $(127-143)$ & $(132-140)$ & $(127-143)$ & $\mathbf{0 , 0 0 6}$ \\
\end{tabular}

NE/LE: nötrofi/lenfosit, MPV/PLT: mean platelet volüm/ platelet

Çalışmamızda ROC-curve analiz sonucunda (Grafik 1) roc-curve eğrisi altında kalan alan \% 67,6 (0,589-0,754) olarak hesaplanmış olup elde elden cut-off değer \% 67,6 oranında doğru cevap vermektedir. Elde edilen cut-off değerine göre sodyum değeri 134 ve altında ise $\%$ 50,0 sensitifite ve \% 84,0 spesifite ile kişinin FN riski taşıdığ tespit edilmiştir (p: 0,001). FN'de risk faktörlerine regresyon analizi ile kendi içlerinde baktığımız zaman sadece sodyum değerinin FN geçirmek için bağımsız bir risk faktörü olduğu tespit edildi (p: 0,003) (Tablo 3).

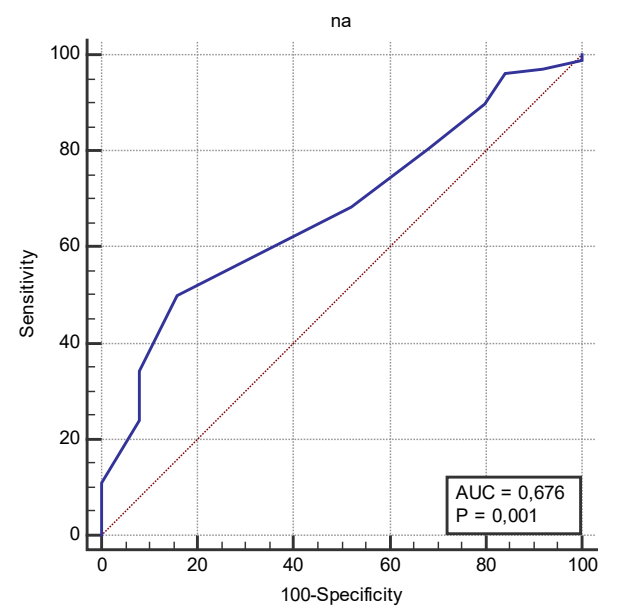

Grafik 1: Sodyumun febril nöbetlerde bağımsız bir risk faktörü olduğunu gösteren ROC-curve analizi

Nötrofil-lenfosit oran1, platelet belirteçleri ve sodyum düzeyi - Sar1geçili ve ark.
Tablo 3: NE/LE ve MPV/PLT oranları ile sodyumun regresyon analizi ile değerlendirilmesi

\begin{tabular}{|c|c|c|c|c|}
\hline \multirow[t]{2}{*}{ Ölçümler } & \multirow[b]{2}{*}{$\mathbf{p}$} & \multirow{2}{*}{$\begin{array}{l}\text { Univariate } \\
\text { HR (95\% } \\
-\mathrm{Cl})\end{array}$} & \multicolumn{2}{|l|}{ Multivariate } \\
\hline & & & $\mathbf{p}$ & \\
\hline \multirow[t]{3}{*}{ NE/LE } & $<1,9758$ & \multirow{3}{*}{0,418} & 1,000 & \multirow{3}{*}{0,350} \\
\hline & & & & \\
\hline & $>1,9758$ & & $1,611(0,592-4,385)$ & \\
\hline \multirow{2}{*}{$\begin{array}{l}\text { Sodyum } \\
(\mathrm{mEq} / \mathrm{L})\end{array}$} & $\leq 134$ & \multirow[b]{2}{*}{0,003} & 1,000 & \multirow[b]{2}{*}{0,007} \\
\hline & $>134$ & & & \\
\hline \multirow[t]{2}{*}{ MPV/PLT } & $\leq 0,033$ & \multirow[b]{2}{*}{0,345} & 1,000 & \multirow[b]{2}{*}{0,447} \\
\hline & $>0,033$ & & $0,696(0,274-1,771)$ & \\
\hline
\end{tabular}

NE/LE: nötrofi/lenfosit, MPV/PLT: mean platelet volüm platelet

Çalışmamızda çocuk acil servisine FN ile başvuran hastaların \% 65.2'nin sodyum değeri 135 altı idi (Tablo 4 ve 5). Tek komplike ya da basit FN geçirenler ile farklı ya da aynı zamanda iki ya da üzerinde FN geçiren hastaların sodyum düzeyleri arasında anlamlı bir farklılık tespit edilmedi (Tablo 4). Ancak komplike ya da basit FN geçiren hastaların sodyum düzeyleri arasında anlamlı fark mecuttu (p: 0,038) (Tablo 5).

Tablo 4: Tek nöbet ve iki ya da üzerinde nöbet geçiren hastaların sodyum düzeyi ile olan ilişkisi

\begin{tabular}{lcccc}
\hline Sodyum grubu & Tek Nöbet & iki ya da üzeri nöbet & Toplam & p \\
& (n: 99) & (n: 39) & (n: 138) & \\
\hline $\mathbf{1 3 5} \mathbf{~ m E q / L ~ a l t ı ~}$ & $68(68,7)$ & $22(56,4)$ & $90(65,2)$ & 0,173 \\
$\mathbf{1 3 5} \mathbf{~ m E q / L ~ v e ~ u ̈ s t u ̈ ~}$ & $31(31,3)$ & $17(43,6)$ & $48(34,8)$ & \\
\hline
\end{tabular}

Tablo 5: Basit ve kompleks FN ile Sodyum düzey ilişkisi

\begin{tabular}{|c|c|c|c|c|c|}
\hline & & Basit FN & Kompleks FN & Toplam & \\
\hline & & $n(\%)$ & $n(\%)$ & $n(\%)$ & $\mathbf{p}$ \\
\hline \multirow{3}{*}{ NA } & $\begin{array}{c}135 \mathrm{mEq} / \mathrm{L} \\
\text { altı }\end{array}$ & $77(69,4)$ & $13(48,1)$ & $90(65,2)$ & \multirow{3}{*}{0,038} \\
\hline & & & & & \\
\hline & $\begin{array}{c}135 \mathrm{mEq} / \mathrm{L} \\
\text { ve üstü }\end{array}$ & $34(30,6)$ & $14(51,9)$ & $48(34,8)$ & \\
\hline
\end{tabular}

\section{Tartışma}

FN'ler çocukluk çağında sık karşılaşılan etyolojisi tam olarak belli olmayan ancak genetik ya da inflamatuar nedenlerin sorumlu tutulduğu klinik durumdur. İnflamatuar durumların nöronal eksitabiliteyi artırdığı ve nöbet eşiğini düşürdüğü düşünülmektedir. FN'lerin etyolojisinde özellikle artan sitokinlerin TNF alfa, IL6, IL1B, IL-10 gibi mediatörlerin sorumlu olduğu tahmin edilmektedir $(9,10)$. Bunlardan özellikle IL1-B'nın FN'de nötrofil sayısını artırdığı ve lenfosit sayısını ise düşürdüğü düşünülmektedir. Acil servise FN nedeni ile başvuran hastalarda basit ya da komplike FN ayrımını yapabilmek bu hastaların gelecekteki epilepsiye dönüşme risklerinin belirlenebilmesi açısından çok önemlidir. Acil servise başvurduklarında ailelerden alınan anamnez ile bu durumun basit ya da komplike FN olduğunun ayrımı her zaman net yapılamamaktadır. $\mathrm{Bu}$ nedenle bu durumu ayırt etmeye yarayan parametrelere ihtiyaç

Genel Tip Derg 2021;31(3)216-220 
duyulmaktadır. Çalışmamızda FN'de akut inflamatuar mediatörlerin basit ya da kompleks FN ayrımını sağlamadaki rolü araştırıldı. Hastaların acil servise başvurularından en fazla bir saat sonra alınan kan değerlerinde NE/LE oranları ya da MPV/PLT oranları arasında basit ya da komplike FN arasında anlamlı farklılık olmadığı görüldü. Özkale ve ark. (11) yaptıkları çalışmada FN'den 1 saat sonra bakılan MPV ve PDW değerlerinde komplike grupta basit gruba göre daha fazla artış; trombosit sayısında ise tam tersi bir azalma olduğunu göstermişlerdir. Yiğit ve ark. da Göksügür ve ark. gibi $(12,13) \mathrm{NE} /$ LE oranlarının basit ve komplike FN grupları arasında anlamlı farklı olduğunu; komplike grupta daha yüksek olduğunu göstermişlerdir. Ancak bu her iki çalışmada da basit ve komplike vaka sayıları birbirlerine oldukça yakındır. Liu ve ark ise (14) çalışmamızla benzer şekilde MPV/PLT'nin basit ya da komplike FN ayrımını sağlamada etkisini gösterememişlerdir. Çalışmamızda NE/LE ve MPV/PLT oranlarının basit ya da komplike FN ayrımında etkisini gösteremedik. Her iki durumunda da etyolojisinde artan sitokinlerin, inflamatuvar mediatörlerin ortak mekanizma olmasına ve komplike nöbet geçiren hasta grubunun basit tipe göre sayıca oldukça az olmasına bağlı geliştiğini düşünmekteyiz. Eğer çalışmamızda FN grubu ile sağlıklı kontrol grubu kıyaslanmış olsa idi FN grubunda anlamlı bir fark ortaya çıkabileceğini düşünmekteyiz. Ayrıca hastaların basit/komplike FN ayrımları hastalardan alınan bilgilere, onların söylediği nöbet süresine ve şekline bağlı olarak yapılması sebebi ile bu durumun çalışmada kısıtll1ık meydana getirdiğini düşünmekteyiz.

Çalışmamızda sodyum düzeyinin 134 ve altı olmasının \% 50 sensitifite ve \% 84 spesifite ile FN ile ilişkili olduğu görüldü (p: 0,001). Acil servise FN geçirerek başvuran 90 (\% 65,2) hastanın sodyum değeri 135 altı idi. Bu durum da hiponatreminin FN için bağımsız bir risk faktörü olduğunu göstermektedir. Ayrıca basit ve kompleks FN durumları arasında sodyum değerleri bakımından anlamlı fark mevcuttu (p: 0,038). Ancak tek FN geçirenler ile iki ya da daha fazla FN geçiren hastalar arasında sodyum değerleri bakımından anlamlı farklılık tespit edilmedi. Bizim çalışmamızda ilk 24 saat içinde nöbetleri tekrarlayanlar ile farklı zamanlarda tekrarlayan FN geçiren hastalar birlikte değerlendirilmiş olması nedeni ile rekurrens yönünden anlamlı farklılık görülmediğini tahmin ediyoruz. Ayrıca, hiponatreminin nöronal hipereksitabiliteyi artırmasına bağlı olarak ateşli çocuklarda nöbete bir yatkınlık oluşturduğunu düşünmekteyiz. Dilber ve ark (15) çalışmamızla benzer şekilde FN'de hiponatremi görülmesinin sık olduğunu ve hiponatremi arttıkça nöbet tekrar sayısının da arttığını belirtmişlerdir. Suryawanshi ve ark (16) ise 55 hastayı değerlendirmiş ve çalışmamıza benzer şekilde \% 72,7 oranında sodyum değerinin 135 ve altı olduğunu göstermişlerdir. Zifman ve ark. (17) ise gastroenterit sonrası gelişen 1lımlı hiponatreminin uzamış nöbet süresi ile ilişkili olduğunu göstermişler ancak nöbet tekrarı ile ilişkisini gösterememişlerdir. Heydarian ve ark. (18) ise hiponatreminin rekurrensle ilişkili olmadığını ama basit FN'de sıklığının daha yüksek olduğunu göstermişlerdir. Acharaporn ve ark. (19) ise hiponatreminin FN rekurrens sıklığını özellikle ilk 24 saatte artırdığını belirtmişlerdir. Kubata ve ark (20) ise çalışmalarında hiponatreminin FN rekurrensi ile ilişkisini gösterememişler ancak bu çalışmada vaka sayısı 51 olup sayının yetersizliğinden kaynaklanmış olabileceğini düşünmekteyiz. Biz çalışmamızda ateşli hastalar ile ya da sağlıklı kontrol grubu ile FN grubunu kıyaslamadık, hasta grubumuzun hepsinin FN geçiren hastalar olması sebebi ile hiponatreminin genel olarak FN'e yatkınlı meydana getirdiğini düşünmekteyiz. Bu sebeple ateş sebebi ile acil servislere başvuran hastalarda eğer dehidrate değil ise gereksiz mayi uygulamasından kaçınılması gerektiğini de düşünmekteyiz.
Sonuç olarak çalışmamızda çocuk acil servise başvuran 138 FN hastası retrospektif olarak değerlendirildi. Basit ya da komplike FN ayrımında NE/LE ya da MPV/PLT oranları arasında anlamlı fark tespit edilmedi. Ancak hiponatreminin FN ortaya çıkmasında bağımsız bir risk faktörü olduğu, sodyumun basit FN grubunda komplike FN grubuna göre daha düşük olduğu ancak bu durumun FN rekurrensi ile ilişkili olmadığı görüldü. Ayrıca ateşli çocuklarda hiponatreminin nöbete yatkınlık oluşturan bağımsız bir risk faktörü olması sebebi ile ateşi olan hastalarda FN riskinin de tahmin edilebileceğini düşünmekteyiz.

Çalışmanın kısıtlııkları: Retrospektif olması, daha detaylı ve daha fazla hasta grubunda çalışma yapılması gerekliliği, ailelerin anamnezleri ile basit/komplike FN kararı verilmesi

Kısaltmalar: FN: febril nöbet, NE/LE: nötrofil/lenfosit, Mean platelet volüm/platelet: MPV/PLT

Çıkar Çatışması: Yazarlar bu yazının hazırlanması ve yayınlanması aşamasında herhangi bir çıkar çatışması olmadığını beyan etmişlerdir.

Finansman: Yazarlar bu yazının araştırma ve yazarlık sürecinde herhangi bir finansal destek almadıklarını beyan etmişlerdi.

\section{Kaynaklar}

1. Natsume J, Hamano SI, Iyoda K, et al. New guidelines for management of febrile seizures in Japan. Brain Dev 2017;39:2.

2. Hesdorffer DC, Benn EK, Bagiella E, et al. Distribution of febrile seizure duration and associations with development. Ann Neurol 2011;70:93.

3. Berg AT, Shinnar S. Complex febrile seizures. Epilepsia 1996;37:126.

4. Fana LL, Wanga YJ, Nana CJ, et al. Neutrophil-lymphocyte ratio is associated with all-cause mortality among critically ill patients with acute kidney injury. Clinica Chimica Acta 2019;490:207-13.

5. Yavuz S, Ece A. Mean platelet volume as an indicator of disease activity in juvenile SLE. Clin Rheumatol 2014;33:637-41.

6. Imtiaz F, Shafique K, Mirza SS, Ayoob Z, Vart P, Rao S. Neutrophil lymphocyte ratio as a measure of systemic inflammation in prevalent chronic diseases in Asian population. Int Arch Med 2012;5:2

7. Hugen CA, Oudesluys-Murphy AM, Hop WC. Serum sodium levels and probability of recurrent febrile convulsions. Eur. J. Pediatr 1995:154;403-5.

8. Kiviranta T, Airaksinen EM. Low sodium levels in serum are associated with subsequent febrile seizures, Acta Paediatr 1995:84;1372-4.

9. Vezzani A, Moneta D, Richichi C, et al. Functional role of inflammatory cytokines and antiinflammatory molecules in seizures and epileptogenesis. Epilepsia 2002;5:30-5.

10. Dube C, Vezzani A, Behrens M, Bartfai T, Baram TZ. Interleukin- $1 \beta$ contributes to the generation of experimental febrile seizures. Ann Neurol 2005;57:152-5.

11. Özkale M, Erol İ, Özkale Y. Association between platelet indices and febrile seizures in children. J Cukurova Med 2016;41:695-701.

12. Yiğit Y, Y1lmaz S, Akdoğan A, Halhalli HC, Ozbek AE, Gencer EG. The role of neutrophil-lymphocyte ratio and red blood cell distribution width in the classification of febrile seizures. Europ Rev for Med and Pharmacol Sciences 2017;21:554-9.

13. Göksügür SB, Kabakuș N, Bekdaș M. Neutrophil-to-lymphocyte ratio and red blood cell distribution width is a practical predictor for differentiation of febrile seizure types. Europ Rev for Med and Pharmacol Sciences 2014;18: 3380-5.

14. Liu Z, Li X, Zhang M, et al. The role of Mean Platelet Volume/platelet count Ratio and Neutrophil to Lymphocyte Ratio on the risk of Febrile Seizure. Scientific reports $2018 ; 8: 15123$

Nötrofil-lenfosit oranı, platelet belirteçleri ve sodyum düzeyi - Sar1geçili ve ark. 
15. Dilber B, Arslan EA, Şahin S, Esenülkü G, Kart PÖ, Cansu A. Febril nöbette hiponatreminin önemi. JCP 2020;18:53-62.

16. Suryawanshi M, Madavi D, Gandhi P. Associatıon of febrile seizure with hyponatremia a prospectıve study. Paediatrics 2019;8:8160.

17. Zifman E, Alehan F, Menascu S, et al. Clinical Characterization of GastroenteritisRelated Seizures in Children: Impact of Fever and Serum Sodium Levels. Journal of Child Neurology 2011;26:1397-400

18. Heydarian F, Ashrafzadeh F, Kam S. Simple febrile seizure: the role of serum sodium levels in prediction of seizure recurrence during the first 24 hours. Iran J Child Neurol 2009;3:31-4.

19. Maksikharin A, Prommalikit O. Serum sodium levels do not predict recurrence of febrile seizures within 24 hours. Ped Int child health 2015;35:44-6.

20. Kubotaa J, Higurashib N, Hiranob D, et al. Predictors of recurrent febrile seizures during the same febrile illness in children with febrile seizures. Journ of the Neurol Sci 2020;411:116682. 